\title{
O ENSINO DE CIÊNCIA ACERCA DA EDUCAÇÃO INCLUSIVA EM ANAJÁS-PARÁ
}

\section{ARTIGO ORIGINAL}

SILVA, Esther Cristiane Correa de Araújo da ${ }^{1}$

SILVA, Esther Cristiane Correa de Araújo da. O Ensino de ciência acerca da Educação Inclusiva em Anajás-Pará. Revista Científica Multidisciplinar Núcleo do Conhecimento. Ano 05, Ed. 06, Vol. 02, pp. 05-17. Junho de 2020. ISSN: 2448-0959, Link de acesso: https://www.nucleodoconhecimento.com.br/educacao/ensino-deciencia

\section{RESUMO}

O presente trabalho retrata o ensino de ciências acerca da educação inclusiva em uma escola pública do ensino fundamental dos anos iniciais. O objetivo foi analisar o processo de ensino de ciências diante da educação inclusiva, e os específicos foi apresentar, compreender e explicar esses procedimentos a partir da problemática de: como está sendo aplicado o ensino de ciências diante da educação inclusiva? A pesquisa se deu com estudo bibliográfico e de campo de cunho quali-quantitativo e com aplicação de um questionário com perguntas em aberto para 08 professores. De acordo com os resultados $90 \%$ dos professores afirmaram que utilizam o livro didático como recurso durante as aulas de ciências e que $10 \%$ o foco está no conteúdo; em relação aos desafios $90 \%$ dos professores entrevistados responderam que não há formação relacionada a inclusão a teoria e prática e 10\% falta de apoio da escola e secretaria de educação; nas estratégias: 90\% afirmaram que utilizam apenas o livro didático como ferramenta e $10 \%$ trabalham com projetos da própria escola. Por fim o estudo apresentou fatores negativos e positivos. Quanto aos aspectos positivos,

\footnotetext{
${ }^{1}$ Mestre em Meio Ambiente e Desenvolvimento; Pós-graduada em Gestão Ambiental e Desenvolvimento Sustentável e Ensino de Ciências; Graduada em Pedagogia e Biologia.
} 
as formações estão sendo aplicadas, porém a falta de articulação entre teoria e prática dentro do ensino de ciências e a educação inclusiva. Os fatores negativos mostram que muitos professores estão se limitando em relação aos recursos utilizados durantes a ministração das aulas de ciências, pois a maioria focaliza no livro didático, que muitas das vezes esta desconectado com a realidade do aluno o que faz com que o professor não consiga contemplar a todos principalmente aquele com algum tipo de deficiência, e é importante observar que o professor precisa levar em conta a individualidade de cada um dos seus alunos, para isso se faz necessário trabalhar com o maior numero de recursos possíveis. É importante salientar que cada aluno tem sua a sua particularidade, e que esta precisa ser respeitada dentro de sua diversidade. Diante do estudo ressaltamos a importância de que a secretaria de educação e a escola possam trabalhar de forma articulada de modo a promover formações voltadas a esta temática, e que leve em conta a realidade do seu educando, para que se concretize de maneira integral o processo de ensino aprendizagem.

Palavras-Chave: Ensino, inclusão, aprendizagem, ciências, formação.

\section{INTRODUÇÃO}

O atual quadro da educação no Brasil apesar de muitos avanços está longe do esperado. O que se percebe é que muitas das vezes as escolas ainda focalizam conteúdos fragmentados, que não favorecem a inclusão de valores, sentimentos de solidariedade, responsabilidade social com a questão da inclusão.

Os conteúdos trabalhados não nascem da reflexão da realidade para a geração de uma prática consciente e transformadora dentro da diversidade humana, e o ensino de ciências na educação inclusiva tem um papel fundamental neste processo.

O ensino de ciências e a educação inclusiva são procedimentos que devem ser desenvolvidos no ambiente escolar de forma harmônica e de fácil compreensão, tanto para os alunos "com deficiência" como para os "sem deficiência". Para que juntos possam desenvolver suas habilidades e assim interagir de forma a não serem intolerantes uns com os outros. 
De acordo com a Lei de Diretrizes e Bases da Educação- LDB (1996) que enfatiza que as técnicas e métodos são de acordo com a necessidade, isto é, o ensino deve está voltado para a realidade do discente, a metodologia aplicada na sala de aula deve levar em conta as especificações do sujeito como ser aprendente.

O tema em estudo é o ensino de ciências acerca da educação inclusiva, que visa à inclusão de todos em prol do ensino e aprendizagem, sendo que o aluno que aprende se desenvolve melhor, mas para isso necessita do acompanhamento do docente e o apoio da escola.

Diante do problema em destaque, que foi sobre: como está sendo ministrado o ensino de ciências diante da educação inclusiva em uma escola pública no ensino fundamental nos anos iniciais no município de Anajás-Pa?

A problemática em estudo foi pensada diante da observação que o ensino de ciências está voltado ao ensino dos seres vivos, planeta, lugares e outros, onde a escola explora de forma generalizada, deixando de pesquisar o ambiente dos alunos.

O estudo tem como objetivo geral analisar o ensino de Ciências na perspectiva de uma educação inclusiva em uma escola pública no ensino fundamental nos anos iniciais no município de Anajás-Pa, e os específicos de compreender, apresentar e explicar os processos da educação inclusiva dentro dessa escola.

Este artigo tem sua estrutura em introdução, focalizando sobre a estrutura da pesquisa e sua relevância, em desenvolvimento, nesse é detalhado e explorado desde os objetivos, as análises de estudo e conclusão.

A pesquisa é de campo com caráter bibliográfico qualitativo, quantitativo e descritivo, com a aplicação de questionário aberto para oito professores, com a hipótese focalizada na falta de apoio ao profissional, no livro didático e conteúdos.

A relevância para a sociedade, educação e ciência está no favorecimento e enriquecimento para outras pesquisas em busca de melhoria e aceitabilidade do outro dentro de sua diversidade e diferença. 
E também a importância da prática está ligada a teoria e dentro da temática estarem sempre juntas na formação continuada dos docentes para que tenham um ensino de qualidade e de preferência próximo de sua realidade.

Não devemos esquecer que o ensino de ciência na educação inclusiva promove a preservação de um ambiente saudável e enriquecedor para todos, e que se unidos os desafios e as diferenças serão sanados, pois ao cuidar de si, do outro e do espaço em que vivemos, desenvolvemos humanamente.

\section{A PRÁTICA DOCENTE NO PROCESSO DO ENSINO DE CIÊNCIAS DIANTE DA EDUCAÇÃO INCLUSIVA}

As transformações no ensino de ciências estão sendo atualizadas constantemente, porém os professores estão adaptando-se as transformações, no entanto, há muita dificuldade para aperfeiçoar suas técnicas diante das transformações. Os desafios que a educação inclusiva estão oferecendo no ensino de ciências se relacionam à prática e teoria da metodologia em sala de aula, as formações, e também aos materiais didáticos.

Os discentes enfrentam várias dificuldades dentre estas, a adaptação ao acolhimento das atividades propostas pelos docentes, mais é importante salientar que a Lei de Diretrizes e Bases da Educação- LDB enfatiza que os discentes com deficiência, transtornos globais do desenvolvimento do educando ou superdotação, os sistemas de ensino assegurarão o direito de ser inserido na rede regular de ensino, a adequação do conteúdo e metodologia aplicada.

I - currículos, métodos, técnicas, recursos educativos e organização específicos, para atender às suas necessidades;

II - terminalidade específica para aqueles que não puderem atingir o nível exigido para a conclusão do ensino fundamental, em virtude de suas deficiências, e aceleração para concluir em menor tempo o programa escolar para os superdotados; 
III - professores com especialização adequada em nível médio ou superior, para atendimento especializado, bem como professores do ensino regular capacitados para a integração desses educandos nas classes comuns;

IV - educação especial para o trabalho, visando a sua efetiva integração na vida em sociedade, inclusive condições adequadas para os que não revelarem capacidade de inserção no trabalho competitivo, mediante articulação com os órgãos oficiais afins, bem como para aqueles que apresentam uma habilidade superior nas áreas artística, intelectual ou psicomotora;

V - acesso igualitário aos benefícios dos programas sociais suplementares disponíveis para o respectivo nível do ensino regular. (LDB,1996, artigo 59).

A LDB assegura desde os métodos ao acesso, porém isso é visto na teoria, muitas instituições além de não adaptar a escola para o educando, ainda promove salas de aulas inadequadas a esses educandos.

Além dessa dificuldade diante da adequação no ambiente escolar, a sociedade é cheia de preconceito, porém atualmente estão aprendendo a conviver com as diferenças.

A LDB visa uma educação de qualidade, porém não há um preparo deste profissional de forma continua no sentido de atender a demanda educacional, por isso talvez muitos docentes ainda continuem utilizando métodos clássicos e hierárquicos dentro da sala de aula. Por isso a necessidade de capacitação permanente dos professores, com base na realidade da comunidade á qual a escola está inserida.

A formação deve ser continua e poderá ser planejada de forma diferenciada, deve inserir um acompanhamento junto ao professor e a escola exercendo a teoria na prática, para que juntos possam atingir seus objetivos. 
Cada escola tem sua identidade, e em cada tempo histórico a educação tem seus métodos modificados, onde cada instituição deve se adequar. A sociedade, a forma de aprendizagem o ensino, e outros mudam com o decorrer do tempo, porém alguns ainda continuam pacatos diante dessas transformações, como exemplo, temos algumas prática pedagógica.

A prática pedagógica é o alicerce no processo ensino e aprendizagem, que viabiliza a aceitabilidade do outro para que juntos possam atrelar seus desafios em busca de enfrentamento e superação.

\section{A EDUCAÇÃO INCLUSIVA}

O ensino destaca a inclusão com base nas leis, medidas e outros documentos. Depois da declaração de Salamanca em 1994, foi garantido que todos os alunos com necessidades educativas especiais fossem incluídos no ensino da rede regular.

O termo "deficiência" significa uma restrição física, mental ou sensorial, de natureza permanente ou transitória, que limita a capacidade de exercer uma ou mais atividades essenciais da vida diária, causada ou agravada pelo ambiente econômico e social. (BRASIL, 2001, Art.1)

De acordo com o texto cada indivíduo tem sua individualidade, e a Lei obriga este está incluído no ensino regular todos os alunos com deficiência, e seu direito precisem ser respeitados. As instituições estão aberta a todos, mais ela precisa estar preparada para atender está clientela, o professor precisa aperfeiçoar suas estratégias de educação com base no discente, respeitando as suas individualidades.

O professor deve lembrar que a classe é heterogenia em seus aspectos sociais, econômicos e culturais, por esse motivo, cabe ao professor realizar a articulação entre conteúdo e a aprendizagem do aluno. A instituição é uma área escolar de autenticidade excepcional em um andamento de multiplicidade, devido a isso, deve seguir o que rege a Lei. 
Certamente não existe uma regra geral para construirmos esta escola que queremos - uma escola para todos. Mas podemo-nos aproximar cada vez mais dela, se encararmos as transformações das escolas que existem hoje da forma mais realística possível, abolindo tudo que nos faz pensá-las e organizá-las de acordo com modelos que as "idealizam", como temos feito até então. (MANTOAN, 2006, p. 206).

Segundo o texto acima, a instituição é para todos, desconstruindo o padrão clássico, enfatizando um pensamento transformador, que o indivíduo possa interatuar e questionar juntamente com o outro dentro dos seus limites e diferenças.

A ação educativa vive em ordenado de alteração, contudo jamais se faz didática em segundos, mas juntamente com paciência e apoio de todos. A didática inclusiva foi implantada para incluir pessoas com dificuldades no ambiente escolar para que o docente possa realizar atividades de acordo com seu alunado.

A lei exige, porém de forma teórica e simultaneamente, fazendo com que a escola e professor sofram modificações em suas metodologias gerando grandes desafios. $O$ docente ainda hoje tem uma série de dificuldades e contrariedade à frente do ensino inclusivo.

Universalizar para a população de 4 (quatro) a 17 (dezessete) anos com deficiência, transtornos globais do desenvolvimento e altas habilidades ou superdotação, o acesso à educação básica e ao atendimento educacional especializado, preferencialmente na rede regular de ensino, com a garantia de sistema educacional inclusivo, de salas de recursos multifuncionais, classes, escolas ou serviços especializados, públicos ou conveniados. (PNE, 2014-2024, META 4).

Segundo a meta do PNE (Plano Nacional da Educação) universalizar o povo de quatro aos dezessete anos incluindo os alunos com transtorno e deficiência ou superdotação que terão direito ao ensino básico de qualidade para serem atendidos, isto é, a escola deve favorecer um ensino de qualidade a todos independentemente de sua diferença. 
Foi observado que muitos dos docentes e a própria instituição encontram dificuldade em receber esses alunos, devido a não preparação ou não formação adequada para lidar com cada aluno dentro de sua deficiência.

Devemos ressaltar que o docente deve aprimorar e refazer seu planejamento de acordo com sua diversidade em sala de aula, e que somente assim poderá alcançar a meta correspondente ao Plano Nacional da Educação- PNE.

O professor deve passar por formações adequadas a sua prática dentro do ensino de ciências e com o tema inclusão para uma aula plena, além disso, a estrutura escolar é a base da inclusão, adequar à escola de acordo com acessibilidade dos discentes ou professores, porque da mesma forma que existe discente com deficiência, também existe professores e outros atores da comunidade escolar.

\section{ANÁLISE DA PESQUISA}

A presente pesquisa foi realizada em uma escola pública por nome fictício: Escola do Ensino Fundamental "Maria Siqueira" que devido a exigência da gestão em aceitar a pesquisa, foi manter o nome da escola e professores em sigilo, a escola atende aos alunos dos anos iniciais no município de Anajás-Pará. Foram aplicados questionários com três perguntas bases para 08 professores que ministram a disciplina de Ciências nas series iniciais.

Na primeira indagação foi: como está sendo aplicado o ensino de ciências nos anos iniciais do ensino fundamental diante da educação inclusiva?

As respostas de $90 \%$ dos professores responderam livro didático e $10 \%$ conteúdo 
Gráfico 1: Aplicação do ensino de ciências diante da Educação Inclusiva

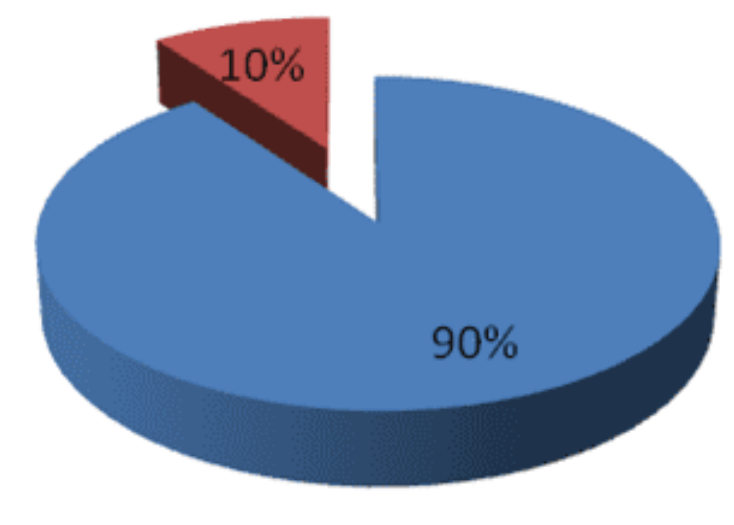

$90 \%$ aplicam o livro didático

$10 \%$ o conteúdo

Fonte: próprio autor (2020).

De acordo com Bardin (2017) visa às premissas categóricas em destaque no livro didático e conteúdo, porém tantos outros recursos que podem ser utilizados, mas a maioria dos professores focaliza no livro didático e no conteúdo como únicos materiais presentes no processo de ensino e aprendizagem.

A integração insere o sujeito na escola esperando uma adaptação deste ao ambiente escolar já estruturado, enquanto que a inclusão escolar implica em redimensionamento de estruturas físicas da escola, de atitudes e percepções dos educadores, adaptações curriculares, dentre outros. A inclusão num sentido mais amplo significa o direito ao exercício da cidadania (SERRA, 2004, p.27).

O sujeito tem direito de ser ensinado da melhor forma e que a formação do docente deve ser realizada da práxis, sendo analisadas as atividades aplicadas em sala de aula, interação aluno e professor nas formações, para que o docente possa criar estratégias diante dos desafios. 
Segunda: qual o desafio enfrentado no processo de ensino de ciências acerca da inclusão? Sendo que $90 \%$ responderam falta de formação relacionando teoria e prática e $10 \%$ falta de apoio da escola e secretaria de educação.

Gráfico 2: O desafio enfrentado no processo de ensino acerca da inclusão

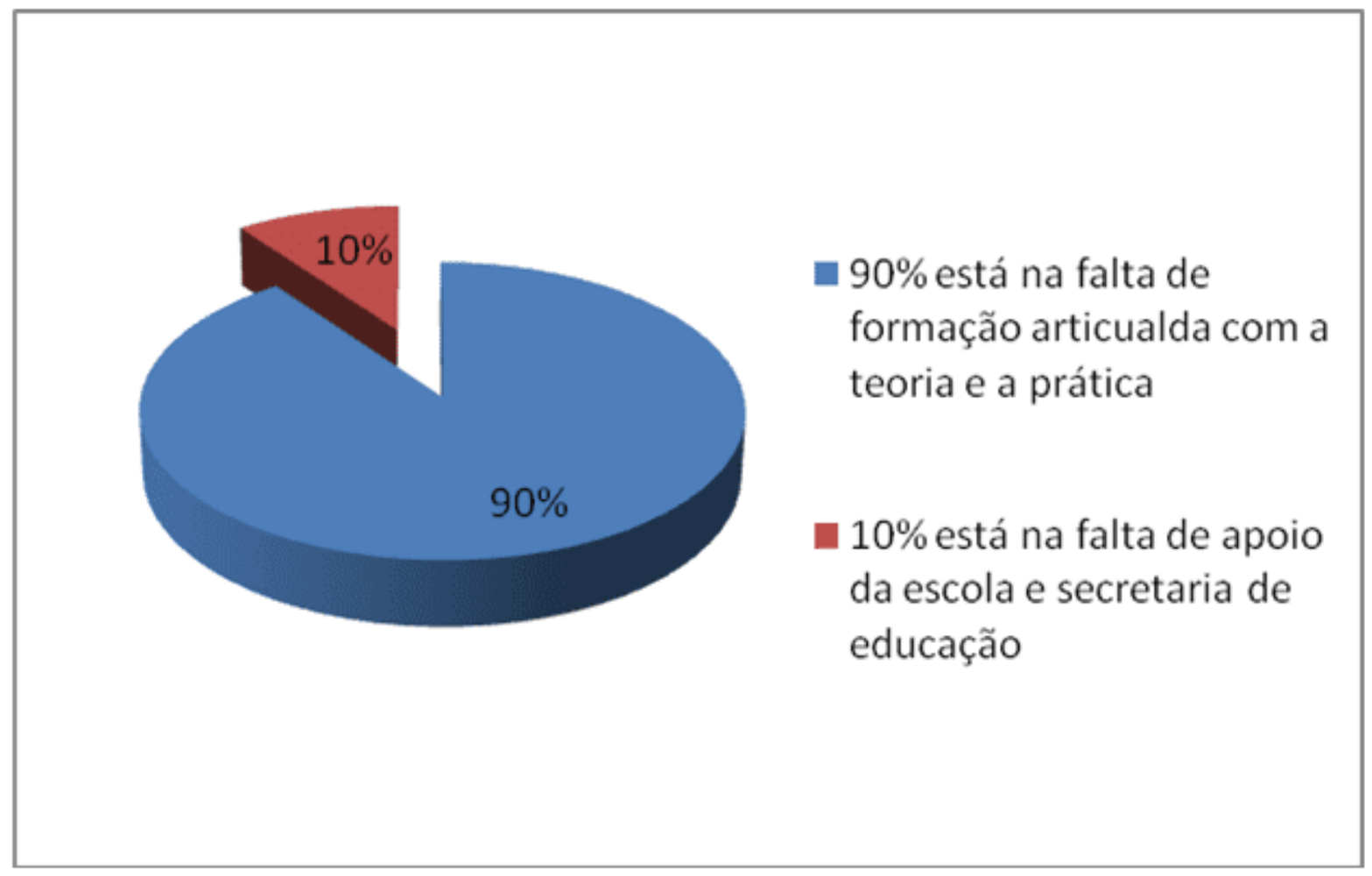

Fonte: próprio autor (2020).

Na segunda questão é um problema de forma generalizada, porque a formação é realizada em teorias, e quando chega para colocar em prática, esquece o que aprendeu na formação. A escola tem papel importante na vida do docente e discente, porém o diálogo entre todos que fazem parte da escola deve haver para que possam tomar as decisões e realizar mudanças em suas práticas pedagógicas.

Pretenderam-se inscrever a escola na ordem das mudanças institucionais exigidas pelo atual momento histórico, é preciso que o projeto político pedagógico assumido pela comunidade escolar esteja estruturado em dois eixos básicos reciprocamente determinantes: A 
intencionalidade política que articula a ação educativa a um projeto histórico, definindo fins e objetivos para a educação escolar; o paradigma epistêmico-conceitual que, ao definir a concepção de conhecimento e a teoria de aprendizagem que orientarão as práticas pedagógicas, confere coerência à proposta, articulando prática e teoria (VEIGA, p.164. 2000).

Entende-se que cada escola além de sua identidade passa por mudanças históricas. A sociedade, o ensino, e a aprendizagem como outros fatores referente ao sujeito e seu meio ocorrem alterações com o decorrer do tempo, porém alguns ainda continuam pacatos diante das transformações, como por exemplos os métodos de ensino.

A prática pedagógica é o alicerce no processo ensino e aprendizagem, que viabiliza a aceitabilidade do outro para que juntos possam atrelar seus desafios em busca de enfrentamento e superação.

A teoria não é realizada na prática, por esse motivo a falta de formação voltada para a inclusão e a falta de apoio ao profissional são categorias que visam os desafios dos docentes diante da inclusão.

Terceira: qual estratégia utiliza no ensino de ciência no processo ensino e aprendizagem? $90 \%$ dos professores utilizam o livro didático e $10 \%$ deles responderam que utilizam projetos. 
Gráfico 3: As estratégias utilizadas no ensino de ciências e processo ensino aprendizagem

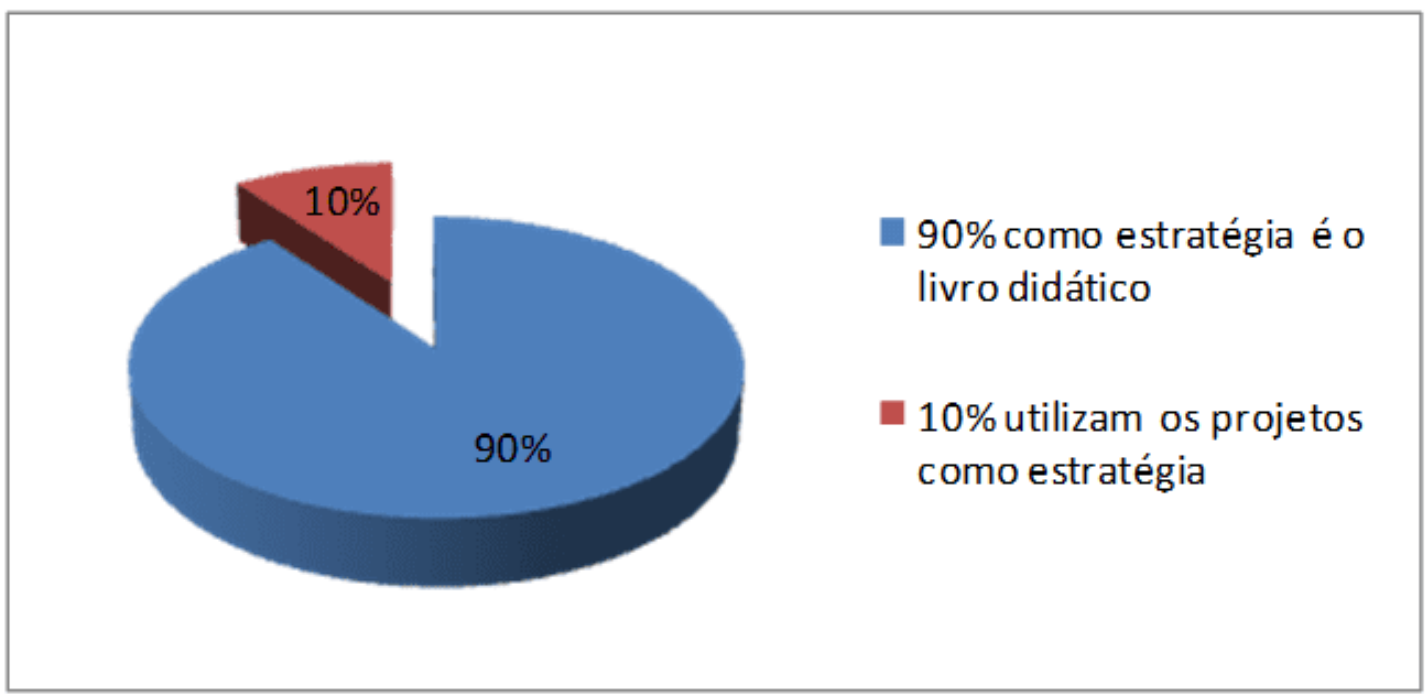

Fonte: próprio autor (2020).

As estratégias que o docente relataram em utilizar no ensino de Ciências, e no processo de ensino e aprendizagem são: o livro didático e projetos, e que ainda relatam estarem cada vez mais desestimulados.

Libâneo (1994) enfatiza sobre a didática do professor em relação ao processo metodológico, que o professor deve organizar de acordo com seu alunado.

Atualmente existem estratégias que não necessitam somente de material comprado pela escola, pode inserir: passeios, observar os objetos ao redor da escola, o cuidar do outro e de sua higiene, assim por diante. A falta da motivação entre vários aspectos entre eles: ensinar diante dos avanços tecnológicos acaba sendo um obstáculo, pois muitos afirmam não ter uma afinidade com a tecnologia.

\section{CONCLUSÃO}

O presente artigo tem sua finalidade em contribuir para com estudos e pesquisas sobre o ensino de ciências acerca da educação inclusiva. $O$ tema enfatiza sobre o ensino de ciências acerca da educação inclusiva. 
O objetivo geral é de analisar o ensino de ciências diante da educação inclusiva no ensino fundamental em uma escola pública no município de Anajás-Pará.

Com base nas análises da pesquisa de campo, o estudo foi analisado dentro do ensino de ciências acerca da educação inclusiva, com o estudo bibliográfico e aplicação de questionário com suas respostas abertas para oito professores que revelaram a defasagem metodológica diante do tema em estudo no processo do aprender e ensinar.

O docente deve focalizar no processo do ensino e da aprendizagem, visto que, o aluno era para ser a premissa do olhar do professor, mas o estudo mostra que a ênfase é o livro didático e o conteúdo, por isso a dificuldade dos discentes com ou sem deficiência em aprender.

Os objetivos específicos foram o de compreender, apresentar e explicar os processos da educação inclusiva. Esses fatores estão presentes no desenvolvimento do trabalho diante da pesquisa bibliográfica relacionando aos autores em estudo.

Compreender, apresentar e explicar a educação inclusiva podem se resumir a uma só frase: aceitar e respeitar o outro como ele é, esse procedimento raramente é visto diante de uma sociedade preconceituosa.

O processo da educação inclusiva é com base nas Leis, que passam para a sociedade o procedimento de inclusão que deve ser respeitado e que cada um deverá fazer sua parte, para que todos possam ser respeitados dentro de suas particularidades ou diferenças.

O problema em destaque foi sobre como está sendo aplicado o ensino de ciências diante da educação inclusiva no ensino fundamental em escolas públicas em município de Anajás- Pará? As análises apresentaram que noventa por cento dos professores utilizam o livro didático como ferramenta didática e dez por cento no conteúdo, apresentou também a falta de formação relacionada com a teoria e prática na inclusão, apoio da escola e secretaria de educação e dez por cento em projetos junto a escola. 
O ensino deve levar em conta a diversidade, e a inclusão de todos, para isso o decente deve se apropriar do maior numero possível de ferramentas para atingir o objetivo do processo de ensino aprendizagem. O mesmo não deve se prender entre paredes da sala de aula ou da escola, deve ir além por isso a importância do professor pesquisador, aquele que desenvolve projetos que envolvam passeios, interações sociais, envolvendo a escola e comunidade escolar e assim sucessivamente.

Dentre as sugestões apresentadas foram, que a secretaria de educação junto à escola possa promover formações ativas na prática e análises das turmas com aluno com deficiência para que o professor além da teoria possa praticar durante as formações e atuar em sala de aula para a melhoria no processo ensino e aprendizagem.

Que os professores promovam projetos, onde cada aluno possa apresentar um projeto de acordo com sua deficiência, mostrando que o ensino de ciência poderá ir além das fronteiras independentemente de ser diferente.

Adequar alunos com ou sem deficiência na mesma pesquisa para que juntos possam transparecer para a sociedade que todos têm suas diferenças, porém nada impede que possam atuar no campo que desejam.

A deficiência não está na parte física ou mental, mas sim nas impossibilidades que o mundo oferece, pois a educação inclusiva e o ensino de ciência mostram que todos são capazes, basta ser motivados e estimulados de maneira lúdica e dinâmica no processo de ensino e aprendizagem.

\section{REFERÊNCIAS}

ASSOCIAÇÃO BRASILEIRA DE NORMAS TÉCNICAS. NBR 6022: informação e documentação: artigo em publicação periódica científica impressa: apresentação. Rio de Janeiro, 2003a.

BARDIN, Laurence. Análise de conteúdo. Tradução Luís Antero Reto. São Paulo: Edições 70, 2017. 
BRASIL, Lei de Diretrizes e Bases da Educação Nacional. MEC. Brasília, 1996.

BRASIL, Ministério da Educação. Diretrizes Nacionais para a Educação Especial na Educação Básica. Secretaria de Educação Especial. MEC; SEESP, 2001.

BRASIL, Educação para Todos. Brasília: Biblioteca Virtual de Educação UNESCOBrasil, 2003.

BRASIL. Lei no 13.005, de 25 de junho de 2014. Aprova o Plano Nacional de Educação - PNE e dá outras providências. Diário Oficial da União, Brasília, DF,26 de junho de 2014. Disponível em: <h $\Sigma$ p://www.planalto.gov.br/ccivil_03/_Ato20112014/2014/Lei/L13005.htm>. Acesso em: 10 de fevereiro de 2020.

LDB - Leis de Diretrizes e Bases. Lei no 9.394. 1996. Disponível em: https://www2.senado.leg.br/bdsf/bitstream/handle/id/529732/lei_de_diretrizes_e_bas es_1ed.pdf. Acesso em 07 de fevereiro de 2019.

LIBÂNEO, J. didática -são paulo: cortez. - (coleção magistério. série formação do professor), 1994.

MANTOAN, M. T. E. Direito de Ser, sendo diferente, na escola. In: RODRIGUES,D. (org). Inclusão e Educação: doze olhares sobre a educação inclusiva. São Paulo: Summus, 2006.

SERRA, Dayse. "A Educação de Alunos Autistas: Entre Discursos e as Práticas Inclusivas das Escolas Regulares". Universidade do Estado do Rio de Janeiro. 2004.

VEIGA, IIma P. Alencastro. Perspectiva para reflexão em torno do projeto político pedagógico, In: Escola: espaço do projeto político-pedagógico. Campinas, SP: Ed. Papirus, 2000. 


\section{ANEXO}

\section{Questionário para docentes}

Uma base de análise para elaboração de um artigo

3. Como está sendo aplicado o ensino de ciências nos anos iniciais do ensino fundamental diante da educação inclusiva?

4. Qual o desafio enfrentado no processo de ensino acerca da inclusão?

5. Qual estratégia utiliza no ensino de ciência no processo ensino e aprendizagem?

Enviado: Maio, 2020.

Aprovado: Junho, 2020. 